\title{
Teaching of corrosion based on critical evaluation of urban furniture of a public square
}

\author{
Fernando B. Mainier ${ }^{1}$, Luciane P. C. Monteiro ${ }^{1}$, Fabio Merçon ${ }^{2}$, \\ Pedro Ivo C. Guimarães ${ }^{2}$, Renata J. Mainier ${ }^{1}$ \\ ${ }^{1}$ Escola de Engenharia, Universidade Federal Fluminense, Niterói, RJ, Brazil \\ ${ }^{2}$ Instituto de Química, Universidade do Estado do Rio de Janeiro, Rio de Janeiro, Brazil
}

\begin{abstract}
This work is part of an educational project intended to foster the teaching of chemistry and corrosion in engineering courses, based on the following points: to facilitate and broaden the understanding of corrosion processes and corrosion protection techniques; awaken critical consciousness in the student, based on the necessity of developing and clarifying mechanisms involved in each corrosive process. Corrosion education at the University Federal Fluminense (Brazil) is becoming increasingly important because corrosion problems affect virtually all segments of human activity and the vast majority of these problems could be avoided if anticorrosive techniques and the expertise already established were applied. This study took public squares as the research lab because public urban furnishings (benches, rubbish bins, playgrounds, etc.) and historical monuments are subject to atmospheric corrosion and pollution. The objective is to enable students to develop their skills in the development of the theme "atmospheric corrosion" based on the following points: teamwork; analysis and evaluation of information from observations; decision making from a restricted amount of information; querying technical bibliographies; making technical reports and oral presentations.
\end{abstract}

Keywords: Atmospheric Corrosion, Corrosion, Corrosion Education, Urban Furniture.

\section{INTRODUCTION}

The definition of the word "city" is quite broad and cannot be applied simply to a geographical location on a map. A city can be defined as a demographic, social and economic complex formed by a population engaged in various activities (commercial, industrial, educational and tertiary). It comprises a series of daily events that intertwine with the past and their historical evolution, establishing coordinated community actions that bring with them a terrain with streets, plazas, pavements, car parks and trade areas, etc. Therefore, a constant stream of social events, including trade, services, educational process, the political system, public health, sports actions and others, eternises urban society relations with this geographic built space. Cities in the modern world are centres of production, consumption, waste and pollution that directly or indirectly cause ecological changes on planet Earth. The levels of gaseous pollutants, such as $\mathrm{CO}_{2}, \mathrm{CO}, \mathrm{NO}_{\mathrm{x}}, \mathrm{SO}_{\mathrm{x}}, \mathrm{O}_{3}, \mathrm{HNO}_{3}$ and VOC (Volatile Organic Compounds) are increasing gradually in urban atmospheres [1-4].

The way in which a great city acquires its shape is a subject often discussed in urbanisation sciences. Each city fashions its own logic and configuration from the design of its morphology and scenarios that reflect the social dynamics, which are reflected in the production of the urban space. The city grows in the conception of works of architecture and engineering, fashioning living spaces that can be analysed and understood but which cannot be dissociated from some dominant factors, such as dust, grey concrete, social contrasts, noise, pollution, ugliness, crowding, stress and delinquency, etc.

In the early days of civilisation, the waste from production systems, handmade or semi-industrialised, was released into the environment via watercourses or into the air. There is no doubt that, even at that time, there was concern over foul odours or aggressive fumes caused by such systems, such that both in Greece and ancient Rome, the copper and silver foundries, olive oil factories, slaughterhouses and tanneries were located in uninhabited areas, away from the city. However, with the further growth and spread of cities, such polluting systems had to be continually displaced; the environmental problems continued but the sources were just moved to more distant locations.

In the 1940s-1950s, pollution of the great cities of the world was caused mainly by industrial processes. However, today, the most polluting factor is transport; $70 \%$ of all urban air pollution is accredited to cars, lorries and buses, whereas just $10 \%$ comes from industries and $20 \%$ from other polluting sources. Public squares in big cities are microenvironments, some of which are beleaguered and besieged, seemingly hostages of large buildings and automobiles, whereas others seem to be free to taste the winds coming from the sea.

The proposal of this work, according to the basic ideas of Giordan \& Vecchi [5], is that the development of a learning process based on the construction of didactic models using specific equipment, or even using some everyday objects, in order to create the necessary conditions for experimentation and the 
development of fundamental knowledge of processes and corrosion mechanisms, are at the same time, critical and systemic.

The focus is directed to the critical assessment of atmospheric corrosion affecting urban furniture and monuments in public squares, which are places that should perpetuate the past, present and future as part of the eternal heritage of humanity.

Figure 1 shows aspects of a public square in Rio de Janeiro (Brazil) where the association of pollution and atmospheric corrosion is evident in the processes of deterioration of materials.

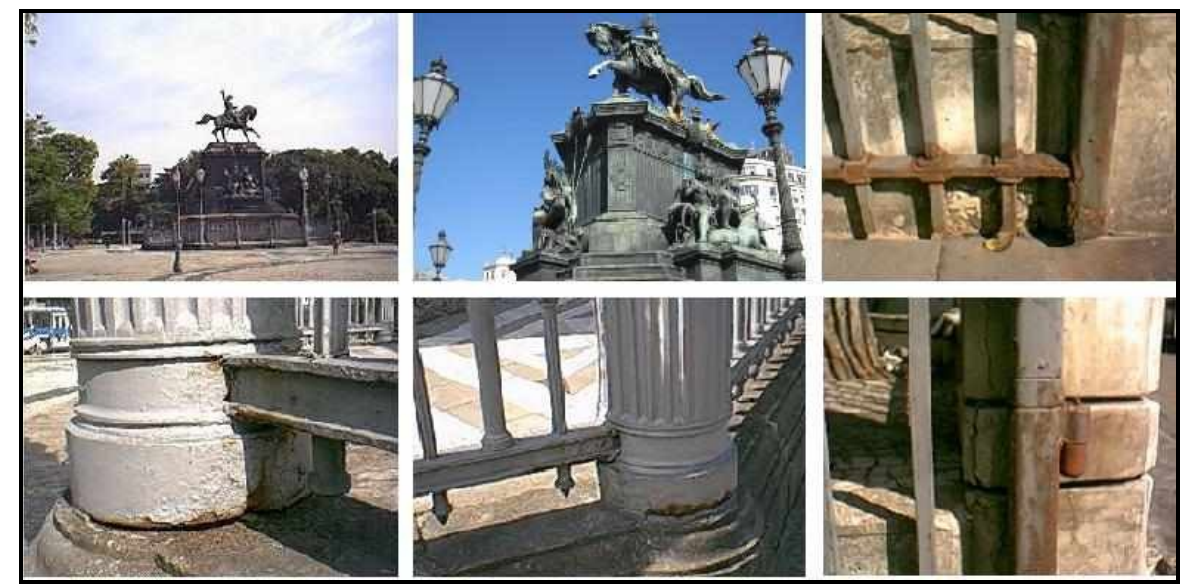

Figure 1 - Aspects of atmospheric corrosion in Tiradentes public square (Rio de Janeiro, Brazil).

Based on this, within the "Introduction to Chemical Engineering" course, a project called "Corrosion in the public square", which examines the knowledge of atmospheric corrosion and environmental pollution, is centred on the following objectives:

- Download the classroom and laboratory for the public square;

- Encourage student contact with everyday life and the environment;

- Identify, interpret, characterise and analyse the principles, laws and mechanisms involved in atmospheric corrosion;

- Encourage natural curiosity;

- Extend the power of the learner to observe, reflect, analyse and develop a sense of searching and questioning;

- Encourage students to research historical data on the squares and monuments.

The development of this learning process aims to facilitate a progressive interpretation of neural events, because there is a need to develop a series of parameters, such as the active and progressive search, selection, operation and integration of new experiences. All these factors aim to expand the conscious mind, which relates to vision-critical knowledge, a fundamental item in the process of interaction and interrelationships between chemistry, corrosion and the everyday.

\section{ATMOSPHERIC CORROSION}

The knowledge of corrosion science and corrosion protection are necessary elements in educating engineering students and therefore, the materials, equipment, industrial safety and the environment are the premises that will accompany their professional trajectory. The literature presents a series of studies involving corrosive action caused by the atmosphere around the world. Several trial programs have sought to identify the causes and determine the indices that directly or indirectly, could serve as a technical reference for corrosion protection.

The aggressive action of the environment and the consequent corrosion protection depends on the following factors:

- relative humidity;

- salinity;

- identification and quantification of pollutant emissions (corrosive gases and particulates);

- dung (mainly birds);

- cyclical variations in temperature; nature of the materials; microclimate;

- residence time of the film electrolyte on materials;

- direction and intensity of air currents;

- precipitation; 
- ultraviolet radiation.

The range of atmospheric corrosion in the literature is broad and varied depending on location and climatic conditions. According to some authors, e.g., Gentil [6]), Roberts [7], Leygraf \& Graedel [8] and Ailor [9], atmospheric corrosion can be classified based on the following types of environment:

- Rural atmosphere: this type of atmosphere is generally the least corrosive and normally does not contain chemical pollutants but does contain organic and inorganic particulates. However, depending on location relative humidity can be high or low;

- Damp atmosphere: regions where the relative humidity is above $60 \%$;

- Wet atmosphere: places where the humidity is close to $100 \%$ and electrolyte condensation occurs on metal surfaces;

- Marine atmospheric: this type of atmosphere is characterised by sodium chloride $(\mathrm{NaCl})$ mists finely deposited on surfaces. Marine atmospheres are usually highly corrosive and the corrosion process tends to be significantly dependent on wind direction, wind speed, precipitation and distance from the coast;

- Urban atmosphere: occurs in neighbourhoods and towns where there is a quantity of gases from the combustion of motor vehicles;

- Industrial atmosphere: places in which industrial units are located; much polluted atmosphere; regions where there are large amounts of polluting industries.

Atmospheric corrosion can be instigated by two types of mechanism: chemical corrosion occurs in the absence of an electrolyte and electrochemical corrosion occurs in the presence of an electrolyte deposited on a metal surface. In the case of a metal or alloy, the corrosion chemistry is a chemical reaction between the metal and corrosive medium, typically a gas free of moisture, resulting in the formation of a product of corrosion on the surface of the metal.

The example shown in the Figure 2 shows an iron plate reacting with anhydrous hydrogen sulphide gas $\left(\mathrm{H}_{2} \mathrm{~S}\right)$ in the absence of moisture [10]. The mechanism of corrosion occurs in two stages: initially, it occurs with gas adsorption $\left(\mathrm{H}_{2} \mathrm{~S}\right)$ on the surface of the iron and later through the chemical attack of the corrosion product, which is a film of ferrous sulphide (FeS).

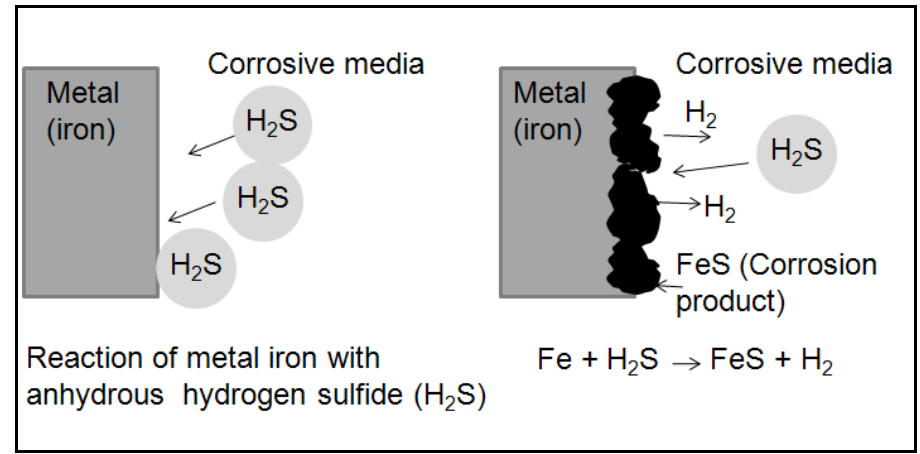

Figure 2 - Chemical corrosion mechanism

The formation of an almost impermeable film on the metal surface could inhibit or prevent the continuation of corrosive process; this is called passivation. Other metals, such as cadmium, copper, silver and zinc are also subject to the same corrosive mechanisms represented by the following reactions:

$$
\begin{aligned}
& \mathrm{Cd}+\mathrm{H}_{2} \mathrm{~S}(\mathrm{~g}) \rightarrow \mathrm{CdS}+\mathrm{H}_{2} \\
& \mathrm{Cu}+\mathrm{H}_{2} \mathrm{~S}(\mathrm{~g}) \rightarrow \mathrm{CuS}+\mathrm{H}_{2} \\
& \mathrm{Zn}+\mathrm{H}_{2} \mathrm{~S}(\mathrm{~g}) \rightarrow \mathrm{ZnS}+\mathrm{H}_{2}
\end{aligned}
$$

The electrochemical corrosion transfer of electrons from the anode to the cathode region is done by means of a metallic conductor and a diffusion of anions and cations in solution closes the electrical circuit. The intensity of the corrosion process is determined by the number of ions that discharge in the cathode, or by the number of electrons that migrate from the anode to the cathode, according to the model and the reactions involved (Figure 3). 


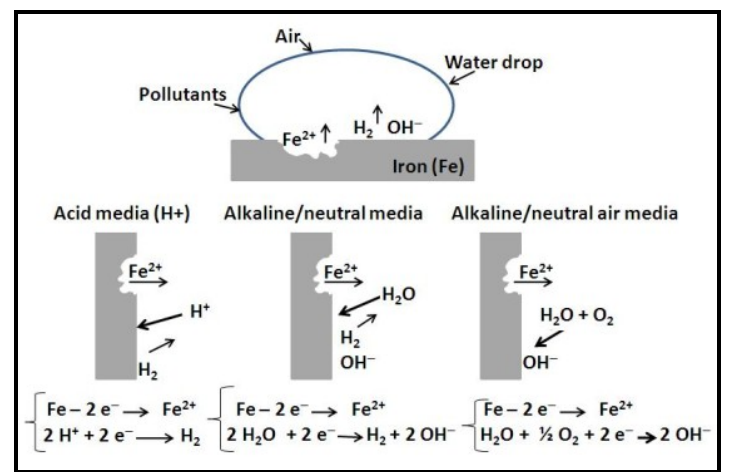

Figure 3 - Electrochemical corrosion mechanism for atmospheric corrosion.

The mechanisms listed above show the electrochemical reactions that occur in metals and alloys, exposed to corrosive media (three principals: acid, alkaline or neutral not airy and airy means alkaline or neutral). The chemical makeup of the corrosive product will depend on the material and consequently, on the constituents of the corrosive medium. The atmospheric pollutants are from various primary and secondary sources resulting in various corrosive gases, such as $\mathrm{SO}_{2}, \mathrm{SO}_{3}, \mathrm{CO}_{2}, \mathrm{NO}_{\mathrm{x}}$ and $\mathrm{H}_{2} \mathrm{~S}$ [10-12], etc. The corrosion products for carbon steel are of various shapes and colours ranging from yellow to black. The main iron oxides found in deposits are $\mathrm{FeO}, \gamma \mathrm{FeOOH}, \mathrm{Fe}_{2} \mathrm{O}_{3}, \mathrm{Fe}_{2} \mathrm{O}_{3} \cdot \mathrm{H}_{2} \mathrm{O}$ and $\mathrm{Fe}_{3} \mathrm{O}_{4}$. The products of corrosion of copper and its alloys exhibit various colours. Copper oxides $\left(\mathrm{Cu}_{2} \mathrm{O}, \mathrm{CuO}\right)$ and copper salts $\left(\mathrm{CuSO}_{4}, \mathrm{CuCl}_{2}, \mathrm{Cu}(\mathrm{OH})_{2} . \mathrm{CuCl}_{2}\right)$ present various colours such as black, blue and green.

Of the various pollutants detected in the atmosphere, since the 1950s, the sulphur compounds have been considered those that most affect human life. Sulphur dioxide $\left(\mathrm{SO}_{2}\right)$, hydrogen sulphide $\left(\mathrm{H}_{2} \mathrm{~S}\right)$, mercaptans (R-SH) and sulphuric acid $\left(\mathrm{H}_{2} \mathrm{SO}_{4}\right)$ are the most common forms found in the atmosphere, although $\mathrm{SO}_{2}$ is the most widely known and determined in all parts of the world $[2,13]$.

Recent research has shown a considerable increase in the quantity of $\mathrm{SO}_{2}$ emitted from industrial complexes. This has led to quite significant damage in Europe and currently, these costs are estimated at several billion dollars per year.

Therefore, all these potential pollutants end up in a cycle of pollution $\rightarrow$ corrosion $\rightarrow$ pollution, generating problems intrinsic to cities and populations. It is important to note the concern that is developing in Brazil for the preservation of historical monuments and urban furnishings, such that future generations could have a heritage that they can respect forever.

\section{DESCRIPTION OF EduCATIONAL Project}

Essentially, the project consists of the following steps:

- Choice of squares and public parks that should be evaluated by groups;

- The groups comprise 4 or 5 students;

- Selection of the components of urban furniture to be photographed and examined;

- Equipment: digital camera, portable pH meter, thickness gauge paint, etc.

- Corrosion waste collection for further analyses;

- Preparation of the report and seminars.

The objective is that students are able to develop essential skills, using basic knowledge of atmospheric corrosion, for training based on the following points:

- Team work;

- Analysis and evaluation of information from observations;

- Decision making from a restricted amount of information;

- Querying technical bibliographies; making technical reports;

- Preparation of audio-visual presentation, exploring techniques including the use of "software";

- Oral presentation of the research work using Microsoft PowerPoint.

\section{RESULTS}

The class of 25 students studying the course "Introduction to Chemical Engineering" was divided into five groups. The public square "Nilo Peçanha", located at the convergence of the streets Passo da Pátria and Presidente Domiciano in Niterói (Rio de Janeiro, Brazil) was chosen as the study area and the location is shown in the picture from Google Maps (Figure 4). 


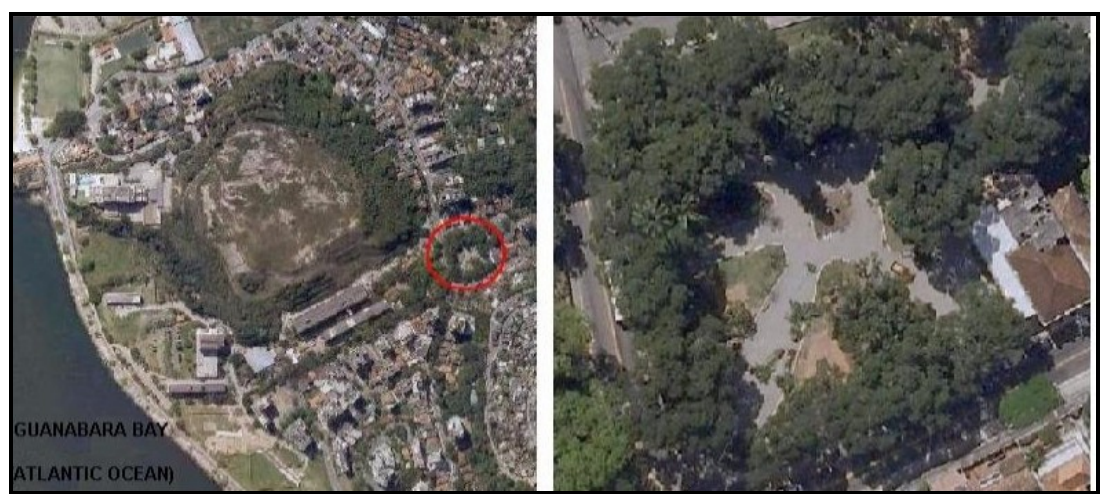

Figure 4 - Location and detail of Nilo Peçanha public square (Niteroi, Rio de Janeiro, Brazil). Google maps.

The students were accompanied by a teacher who proposed an action strategy to each group, which consisted of the following steps:

- General assessment of the square and photo identification of monuments, plaques, garden benches, bins, toys, etc;

- Corrosion product recall for analysis in the laboratory;

- Bibliographic research on atmospheric corrosion and correlations involving pollution and environment;

- Historical research and evaluation of social and political performance of writer Nilo Peçanha;

- Preparation of the report;

- Preparation of the seminar presentation using multimedia techniques.

Some pictures (Figure 5-16) are presented showing the performance of students in the square trying to identify the problems that are the result of atmospheric corrosion.
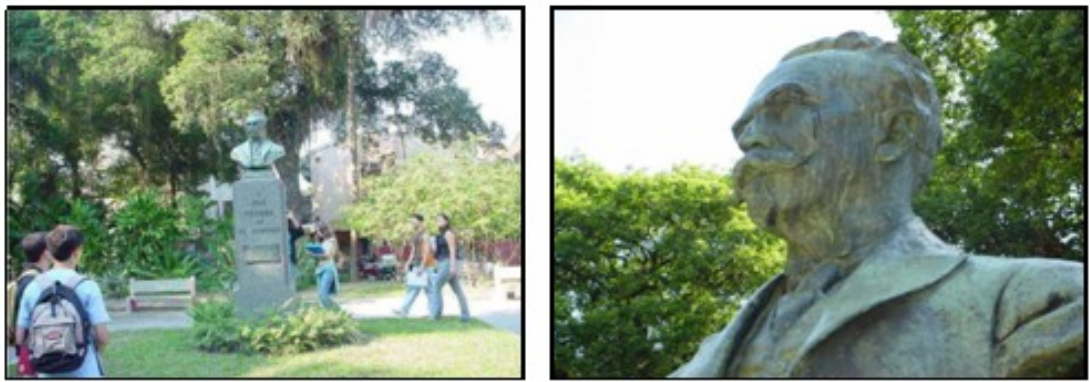

Figures 5,6-The bronze bust of the writer Nilo Peçanha manufactured on October 12, 1927.
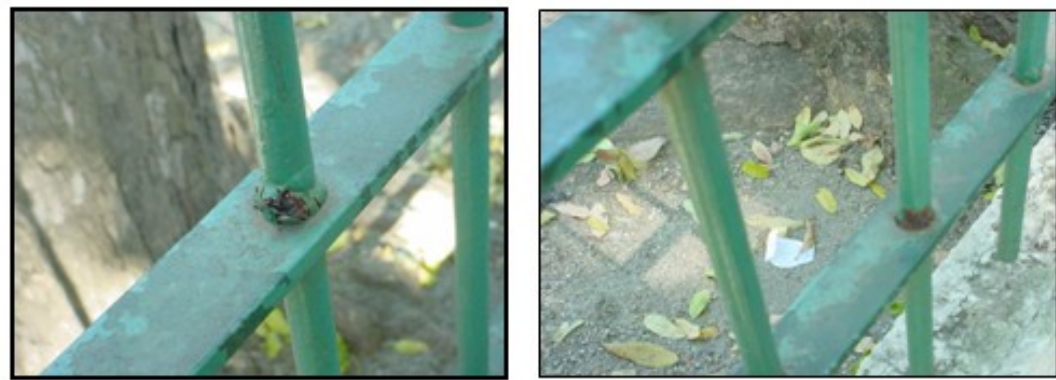

Figures 7, 8 - Aspect in grating corrosion of carbon steel coated with green paint.
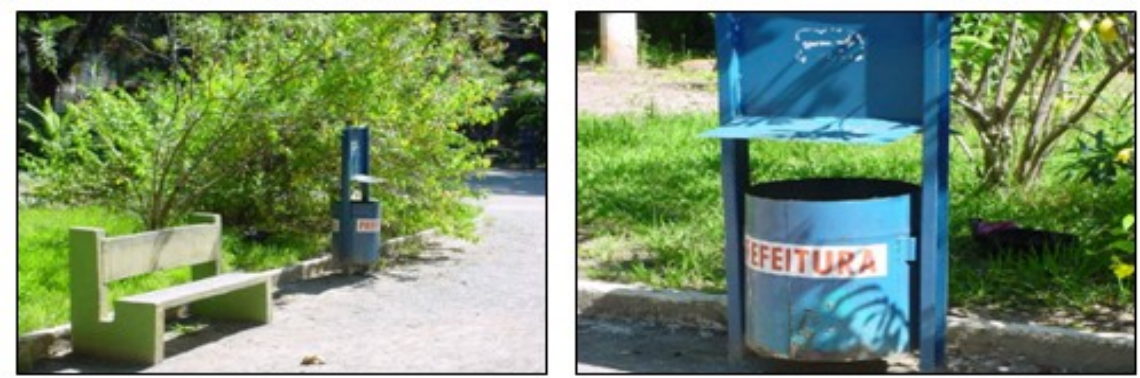

Figures 9,10-Aspect of concrete bench and garbage bin. 

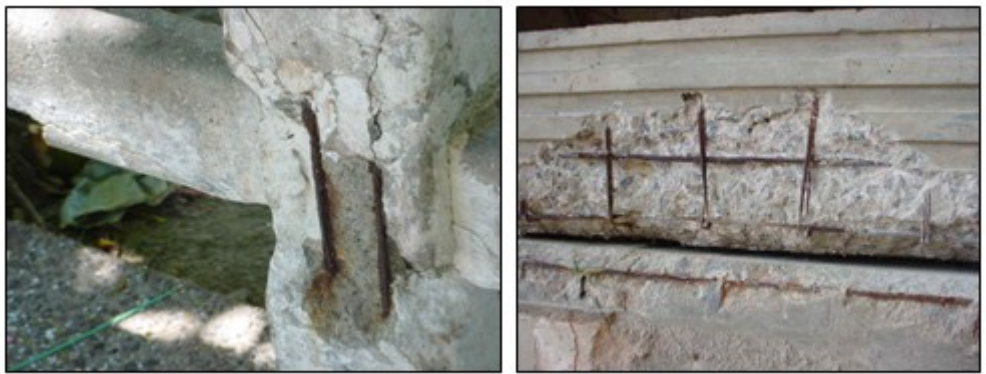

Figures 11, 12 - Appearance of corrosion of concrete by showing the attack on carbon steel by environmental conditions.
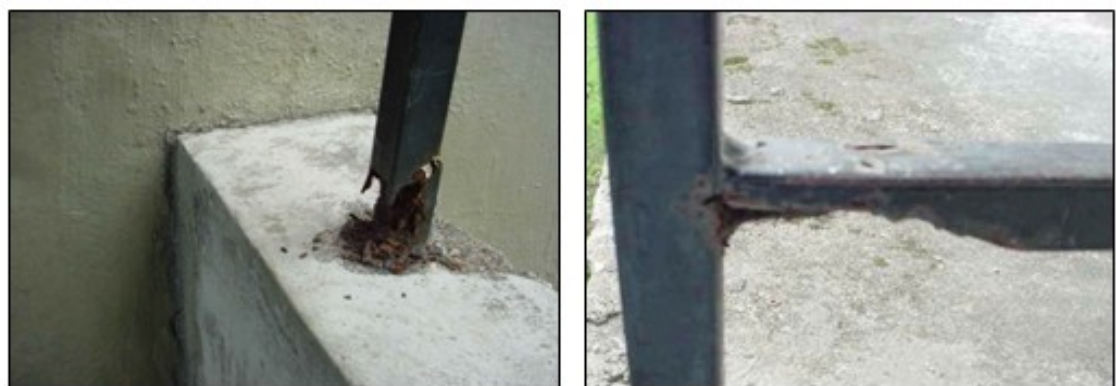

Figures 13, 14 - Appearance of atmospheric corrosion of carbon steel rods.
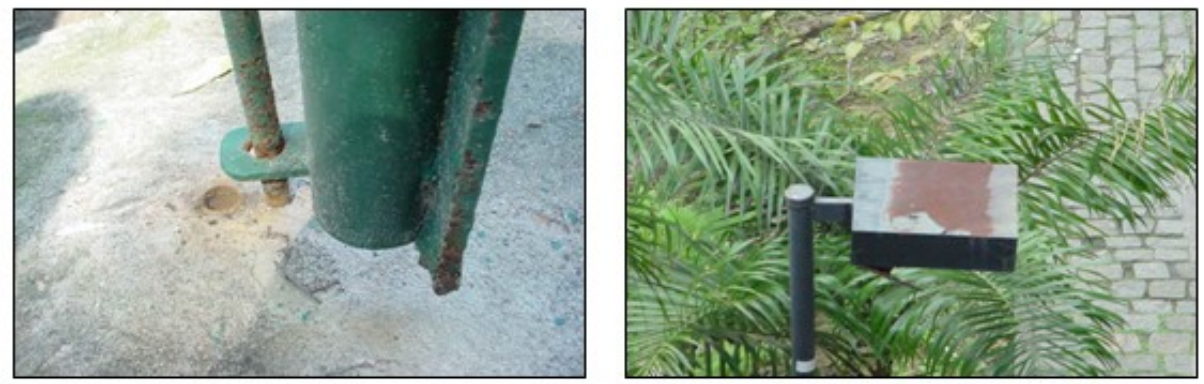

Figures 15, 16 - Atmospheric corrosion of rod and box of carbon steel.

From the photos, it is possible to identify intense atmospheric corrosion. The $\mathrm{pH}$ determined from water droplets deposited on the metallic surfaces presented a result in the range 6.5 to 6.8. Samples removed from the surfaces of carbon steel materials consist primarily of $\mathrm{FeO}, \mathrm{Fe}(\mathrm{OH})_{2}$ and $\mathrm{FeO} . \mathrm{OH}$. The analyses of the waste removed from the bronze bust consisted of $\mathrm{CuO}, \mathrm{CuCl}_{2}, \mathrm{Cu}(\mathrm{OH})_{2} \cdot \mathrm{CuCl}_{2}$.

The evaluation of each group consisted of the following parts:

- The main difficulties encountered by the groups were:

a) Analysis and identification of corrosion products collected from urban furniture;

b) Difficulties of group meetings for discussion and drafting of the final report because of the evidence practice sessions, research papers, etc.

- Discussion of the report:

The reports made by the groups were analysed by the teacher taking into consideration the following items: goals, evaluation of historical writer Nilo Peçanha, a description and evaluation of urban furniture, photographs, bibliographic research, development and completion. Generally, all of these items were answered satisfactorily.

- Final preparation and presentation of the work:

Groups of students prepared the presentation using PowerPoint software and performed the presentation with great aplomb, responding promptly and answering enquiries made by teachers and students.

V.

FinAl CONSIDERATIONS AND CONCLUSIONS

As stated previously, the evaluations carried out in public squares on atmospheric corrosion of securities and monuments sought to highlight the following points:

- Facilitate and broaden the understanding of the processes of corrosion of metallic materials; 
- Awaken in students the need for the development and clarification of the mechanisms governing the corrosive processes;

- Guide students towards research and questioning, giving them basic experience in the type of physicalchemical measurements, which lead to qualitative and quantitative results in relation with the production system;

- Identify and characterise each of the scientific methods used in chemistry and to recognise the meaning of a scientific law;

- Develop in students the need to relate historical facts with the study of cases;

- Awaken in students the importance of leaving the classroom to assess real cases and their correlation with daily life;

- Guide students in relating corrosive processes to the environment;

- Stimulate the desire to search for technological innovation through special projects and if necessary, break from the traditional direction of experiments.

Finally, we can say that the project called "Corrosion in the public square" met completely the educational requirements, allowing students to achieve an understanding of the direct and indirect concepts related to the triad: corrosion-anticorrosion protection-environment.

\section{REFERENCES}

[1] W. H. Graus, and E. Worrel, Effects of $\mathrm{SO}_{2}$ and $\mathrm{NO}_{x}$ control on energy-efficiency power generation, Energy Policy, Volume 35, Issue 7, July, 3898-3908, 2007.

[2] J. R. Mudakavi, Principles and practices of air pollution control and analysis, (New Delhi, India: International Publishing House Pvt, 2010).

[3] C. Dolgorouky, V. Gros, R. Sarda-Esteve, V. Sinha, J. Williams, N. Marchand, S. Sauvage, L. Poulain, J. Sciare, and B. Bonsang, Total OH reactivity measurements in Paris during the 2010 MEGAPOLI winter campaign, Atmospheric Chemistry and Physics, 12, 9593-9612, 2012.

[4] S. Syed, Atmospheric corrosion of materials, Emirates Journal for Engineering Research, 11 (1), 1-24, 2006.

[5] A. Giordan, G. Vecchi, Les origines du savoir des conceptions des apprenants aux concepts scientifiques, (Paris; Delachaux et Niestlé, 1994).

[6] V. Gentil, Corrosão, (Rio de Janeiro: Brazil, LTC - Livros Técnicos e Científicos Editora, 2011)

[7] P. R. Roberge, Handbook of Corrosion Engineering, (New York, McGraw-Hill, 2000).

[8] C. Leygraf, and T. E. Graedel, Atmospheric Corrosion, (New York: John Wiley \& Sons, 2000)

[9] H. W. Ailor, Atmospheric Corrosion, (New York, John Wiley and Sons, 1982).

[10] F. M. Mainier, G. C. Sandres, R. M. Mainier, Integrated management system for in-house control of accidental hydrogen sulfide leaks in oil refineries, International Journal of Science and Advanced Technology, volume 2, issue 9, September, 76-84, 2012.

[11] P. A. Schweitzer, Fundamentals of corrosion: mechanisms, causes, and preventative methods, (New York: CRC Press, 2010).

[12] L. L. Sheir, R. A. Jarman and G. T. Burstein, Corrosion, Volume 2, Third Edition, (Oxford: Butterworth-Heinemann, 2000).

[13] N. B. Grimm, S. H. Faeth, N. E. Golubiewski, C. L. Redman, J. Wu, X. Bai, J. M. Briggs, Global Change and the Ecology of Cities, Science, vol. 319, February, 756-660, 2008. 